\title{
A política de garantia de preços mínimos para o pinhão
}

\author{
Rodrigo Medeiros Ribeiro ${ }^{1 *}$, Anadalvo Juazeiro dos Santos ${ }^{1}$, Alexandre Bittencourt ${ }^{2}$ \\ ${ }^{1}$ Universidade Federal do Paraná, Av. Pref. Lothário Meissner, n 632, Jardim Botânico, CEP 80210-170, Curitiba, PR, Brasil \\ ${ }^{2}$ Banco do Brasil S/A, Quadra CLS 406 Bloco B, Asa Sul, CEP 70255520, Brasília, DF, Brasil
}

*Autor correspondente:
medeirossss@gmail.com

Termos para indexação:

Araucaria angustifolia

Cadeia produtiva

Produtores

Coletores

Index terms:

Araucaria angustifolia

Supply chain

Producers

Collectors

Histórico do artigo:

Recebido em 10 set 2014

Aprovado em 20 ago 2015

Publicado em 31 dez 2015

doi: $10.4336 / 2015 . p f b .35 .84 .782$
Resumo - O pinhão, semente da espécie Araucaria angustifolia (Bertol.) Kuntze, é muito presente nas mesorregiões Sudeste e Centro Sul do estado do Paraná, sendo considerado um dos principais produtos florestais não madeireiros (PFNM) do estado. O comércio de pinhão ocorre de maneira irregular, pois os produtores não têm dimensão exata das mudanças de preços e de como devem alocar seus recursos. Esse processo ocasiona perda, pela diferença dos custos de produção do pinhão e de venda pelos produtores. A política de garantia de preços mínimos (PGPM) consiste em um sistema de preços antecipados estabelecidos pelo Governo Federal cuja função é reduzir ou transferir para a sociedade a incerteza de preços com que se defrontam os produtores no plantio e na colheita. Este trabalho teve por objetivo analisar a economia do pinhão nas mesorregiões Sudeste e Centro Sul do estado do Paraná, para subsidiar a estruturação da cadeia produtiva, e analisar os preços recebidos pelos produtores comparativamente aos custos de produção, para inclusão do pinhão na lista de produtos beneficiados pela PGPM. A subvenção da produção do pinhão apresentou-se como uma ferramenta importante, uma vez que os preços médios pagos aos produtores e extratores se mostraram abaixo do custo de produção para o período estudado.

\section{Minimum price guarantee policy for araucaria seed}

\begin{abstract}
Seed of Araucaria angustifolia (Bertol.) Kuntze species, known as pinhão, is very present in the Paraná Southeast and South Center mesoregions, being considered one of the leading non-timber forest products (NTFP), after erva-mate, in terms of production level and value of production itself. Producers of pinhão do not have the exact dimension of the change in market prices. When prices of pinhão increase, they believe that sell prices will remain high and move their resources to increase production. A disorderly trade practice can cause loss, related to the pinhão production costs and selling price by producers. The minimum price guarantee policy (MPGP) consists in a system of anticipated prices established by the Federal Government, whose function is to reduce or transfer to the community the uncertainty faced by farmers in planting or harvesting. The objectives of this study are: to analyze the economy of pinhão in the Paraná Southeast and South Center mesoregions to support the structuring of the production chain; and to analyze the producers' sell prices in relation to production costs to include pinhão in the list of products benefiting from the MPGP.
\end{abstract}




\section{Introdução}

O pinhão, semente de Araucaria angustifolia, é considerado um dos principais produtos florestais não madeireiros (PFNM) do estado do Paraná, apenas atrás da erva-mate, em termos do valor da produção. De acordo com o IBGE (2010b), a produção nacional de pinhão na safra de 2009/2010 alcançou 5.715 ton, sendo que destes o Paraná participa com cerca de $45 \%$ do volume ofertado.

De acordo com dados do Departamento de Economia Rural da Secretaria de Agricultura e Abastecimento do estado do Paraná (Paraná, 2012) em 2010 foram produzidas no Paraná aproximadamente 4.500 ton de pinhão, sendo que a mesorregião sudeste foi responsável por $32 \%$ da produção paranaense e a mesorregião centrosul por $31 \%$.

A semente de araucária representa uma porção expressiva na economia do estado, sobretudo em regiões de maior pobreza. Há uma reconhecida informalidade na produção e o seu comércio está basicamente segmentado entre produtores, coletores, atacadistas, varejistas e consumidores finais. Não há um número exato de pessoas envolvidas na coleta e comercialização do pinhão no estado. Guerra et al. (2002) destacam sua importância alimentar e fonte de renda para coletores e produtores rurais, entretanto, ainda pouco se conhece sobre as implicações sociais, econômicas e ambientais da atividade de coleta e venda de pinhão no estado do Paraná.

Os produtores de pinhão não têm a dimensão exata da mudança dos preços de mercado, pois quando os valores do pinhão aumentam, acreditam que estes se manterão elevados e deslocam recursos para aumentar a produção. Contudo, na época da colheita o preço tende a cair, caracterizando o emprego excessivo de recursos na atividade. Essa prática desregrada pode ocasionar perda, se comparados os custos de produção do pinhão e o seu preço de venda pelos produtores.

A adoção de políticas que utilizem ferramentas de comando e controle, somada as políticas baseadas em instrumentos econômicos, como exemplo, a política nacional de garantia de preços mínimos (PGPM), pode ser utilizada para alcançar o equilíbrio para os produtores de pinhão. A política de preços mínimos consiste em um sistema de preços antecipados estabelecidos pelo Governo Federal cuja função é reduzir ou transferir para a sociedade a incerteza de preços com que se defrontam os produtores por ocasião do plantio e da colheita. Em outras palavras, é pago ao produtor um valor de subvenção, que se constitui na diferença entre o seu custo de produção e o valor que o produto deveria ser vendido para que o produtor não tenha prejuízo.

Atualmente não há na região Sul do Brasil nenhum produto florestal não madeireiro entre os produtos assistidos pela PGPMBio. Justifica-se então esse estudo para que haja uma maior compreensão e conhecimento dos atores e custos envolvidos no processo produtivo do pinhão.

Este trabalho tem por objetivo analisar a economia do pinhão nas mesorregiões Sudeste e Centro Sul do estado do Paraná, para subsidiar a estruturação da cadeia produtiva, a partir dos preços recebidos pelos produtores comparativamente aos custos de produção, para inclusão do pinhão na lista de produtos beneficiados pela PGPM.

\section{Material e métodos}

A área de estudo compreende a região sudeste do Paraná, além dos municípios de Turvo, Guarapuava, Inácio Martins e Pinhão, da região centro-sul paranaense. A Mesorregião Homogênea - MRH do Sudeste do estado do Paraná é formada pela união de 21 municípios agrupados em quatro microrregiões denominadas Irati, São Matheus do Sul, Prudentópolis e União da Vitória (Sesc, 2010). Sua composição florestal é definida como Floresta Ombrófila Mista, conhecida pela ocorrência de araucárias (Associação de Preservação do Meio Ambiente e da Vida, 2005).

Segundo o IBGE (2009) a MRH Sudeste possui uma população estimada em aproximadamente 415 mil habitantes e caracteriza-se por possuir quase metade da população residente em áreas rurais. A MRH Sudeste e Centro-Sul apresentam predominantemente o clima Subtropical Úmido Mesotérmico ( $\mathrm{Cfb}$ ), com principais médias anuais de temperatura dos meses mais quentes inferiores a $22{ }^{\circ} \mathrm{C}$ e dos meses mais frios inferiores a $18{ }^{\circ} \mathrm{C}$. A temperatura média anual é de $16{ }^{\circ} \mathrm{C}$, com chuvas entre $1.600 \mathrm{~mm}$ e $1.900 \mathrm{~mm}$ e umidade relativa do ar de $85 \%$, sem deficiência hídrica. A estrutura fundiária é de pequenas propriedades com atividade familiar (Sesc, 2010). De acordo com o IBGE (2010a) o produto interno bruto (PIB) per capita é de $\mathrm{R} \$ 9.538,42$, inferior ao verificado para o estado, de $\mathrm{R} \$ 15.711,00$.

A coleta de dados ocorreu durante os meses de abril a agosto de 2010, período de safra do pinhão. Os dados 
foram coletados por meio de formulários, os quais são definidos por Gil (2009) como uma pesquisa exploratória qualitativa e quantitativa, seguindo uma técnica de investigação composta por um conjunto de perguntas. As entrevistas foram direcionadas a produtores rurais, coletores, atacadistas e comerciantes dos mais diversos níveis da cadeia produtiva.

Para a análise dos dados de campo utilizou-se estatística descritiva e planilhas eletrônicas para a tabulação e sistematização das informações obtidas por meio da aplicação de questionário, conforme Lopes (1999). Os dados utilizados para realização da pesquisa são de natureza primária e secundária, oriundos respectivamente de levantamentos em campo e pesquisa documental (Gil, 2009). Dentre os dados primários relativos à produção e comercialização estão preços e quantidades produzidas/extraídas e comercializadas em cada segmento da cadeia, renda da propriedade, renda com a comercialização do pinhão, destino da produção e aspectos sociais das famílias de produtores entrevistados. Foram também obtidos dados relacionados à atividade de coleta do pinhão, tempo em que se dedica à atividade, percepções de proprietários e produtores/coletores de pinhão quanto à atividade.

Para obtenção dos dados secundários foram consultados: Instituto Ambiental do Paraná (IAP), Secretaria de Estado da Agricultura e Abastecimento (SEAB), Instituto Paranaense de Desenvolvimento Econômico e Social (IPARDES), Empresa Brasileira de Pesquisa Agropecuária (EMBRAPA), Instituto Brasileiro de Geografia e Estatística (IBGE), Companhia Nacional de Abastecimento (CONAB) e Secretaria de Estado da Ciência e Tecnologia (SETI).

Realizou-se uma amostragem da população, em conformidade com Gil (2009). Os dados obtidos foram analisados estatisticamente, com nível de probabilidade de confiança de $95 \%$ e margem de erro de $10 \%$. Tomouse por base a amostragem estratificada dos dados, na qual é possível dividir uma população heterogênea em subpopulações homogêneas, de modo a diminuir a variação dentro da população e, consequentemente, diminuir o tamanho da amostra necessária (Péllico Neto \& Brena, 1997). Segundos os mesmos autores, a restrição imposta previamente à coleta dos dados permite classificar a amostragem realizada como "aleatória restrita".
As entrevistas foram direcionadas a produtores rurais e coletores de variadas proporções. A suficiência amostral, calculada com base em Péllico Neto \& Brena (1997) e a quantidade de entrevistas realizadas podem ser observadas na Tabela 1.

Tabela 1. Suficiência amostral da pesquisa e quantidade de entrevistados.

\begin{tabular}{ccc}
\hline $\begin{array}{c}\text { Segmento da } \\
\text { Cadeia Produtiva }\end{array}$ & $\begin{array}{c}\text { Número de } \\
\text { entrevistas exigidas }\end{array}$ & $\begin{array}{c}\text { Números de } \\
\text { entrevistas realizadas }\end{array}$ \\
\hline Produtores & 29 & 37 \\
Coletores & 25 & 31 \\
\hline Total & 94 & 254 \\
\hline
\end{tabular}

Foram entrevistados produtores dentro de cada estrato de tamanho de propriedades rurais, conforme definido na Lei no 8.629/93 (Brasil, 1993) e Instrução Especial $n^{\circ} 20$ do Incra (1980). De acordo com estas normas, são estabelecidos módulos fiscais por município e estado, sendo utilizada a média estadual para definição dos três grupos apresentados como:

- Pequenas propriedades: área de até 74,4 ha;

- Médias propriedades: área entre 74,5 e 278,9 ha;

- Grandes propriedades: área superior a 279 ha.

A definição do preço mínimo a ser pago pelos produtos abrangidos pela política nacional de pagamento de preços mínimos é baseada no custo de produção destes produtos. Sendo assim, de acordo com a Conab (2010b) o método de cálculo adotado busca contemplar todos os itens de dispêndio, explícitos ou não, que devem ser assumidos pelo produtor, desde as fases iniciais de correção e preparo do solo até a fase inicial de comercialização do produto.

O cálculo do custo de uma determinada cultura estabelece custos de produção associados aos diversos padrões tecnológicos e preços de fatores em uso nas diferentes situações ambientais. Desta forma, o custo é obtido mediante a multiplicação da matriz de coeficientes técnicos pelo vetor de preços dos fatores.

A estrutura utilizada para a obtenção do custo de produção dos produtos beneficiados pela PGPMBio está apresentada na tabela 2, com dados organizados de maneira a separar os componentes de acordo com sua natureza contábil e econômica. Entretanto, nem todos os itens descriminados estão presentes na atividade extrativista do pinhão. Em termos contábeis, os custos variáveis são separados em despesas de custeio da lavoura, esta última, incidente sobre o capital de giro utilizado. 
Tabela 2. Estrutura de custos utilizada para o cálculo do custo de produção dos PFNM da sociobiodiversidade beneficiados pela PGPMBIO.

\begin{tabular}{|c|c|c|c|}
\hline Discriminação & Valor R\$ & Valor R\$ kg-1 & Part (\%) \\
\hline \multicolumn{4}{|l|}{ I - Despesas de custeio da atividade extrativista } \\
\hline 1 - Operação com avião & 0,00 & 0,00 & 0,00 \\
\hline 2 - Operação com máquinas próprias & 0,00 & 0,00 & 0,00 \\
\hline 3 - Aluguel de máquinas/serviços & 0,00 & 0,00 & 0,00 \\
\hline 4 - Operação com animais próprios & 0,00 & 0,00 & 0,00 \\
\hline 5 - Operação com animais alugados & 0,00 & 0,00 & 0,00 \\
\hline 6 - Mão-de-obra & 0,00 & 0,00 & 0,00 \\
\hline 7 - Mão-de-obra fixa & 0,00 & 0,00 & 0,00 \\
\hline 8 - Sementes & 0,00 & 0,00 & 0,00 \\
\hline 9 - Fertilizantes & 0,00 & 0,00 & 0,00 \\
\hline 10-Agrotóxicos & 0,00 & 0,00 & 0,00 \\
\hline 11 - Outras despesas (luvas, capacete, bota) & 0,00 & 0,00 & 0,00 \\
\hline 12 - Outros itens & 0,00 & 0,00 & 0,00 \\
\hline Total das despesas de custeio (A) & $\mathbf{0 , 0 0}$ & $\mathbf{0 , 0 0}$ & $\mathbf{0 , 0 0}$ \\
\hline \multicolumn{4}{|l|}{ II - Despesas pós-coleta } \\
\hline 1 - Seguro agrícola & 0,00 & 0,00 & 0,00 \\
\hline 2 - Assistência técnica & 0,00 & 0,00 & 0,00 \\
\hline 3 - Transporte externo & 0,00 & 0,00 & 0,00 \\
\hline 4 - Armazenagem & 0,00 & 0,00 & 0,00 \\
\hline $5-\mathrm{CESSR}$ & 0,00 & 0,00 & 0,00 \\
\hline 6 - Impostos & 0,00 & 0,00 & 0,00 \\
\hline $7-$ Taxas & 0,00 & 0,00 & 0,00 \\
\hline 8 - Outros & 0,00 & 0,00 & 0,00 \\
\hline Total das despesas pós-coleta (B) & 0,00 & $\mathbf{0 , 0 0}$ & $\mathbf{0 , 0 0}$ \\
\hline \multicolumn{4}{|l|}{ III - Despesas financeiras } \\
\hline $1-$ Juros & 0,00 & 0,00 & 0,00 \\
\hline Total das despesas financeiras (C) & $\mathbf{0 , 0 0}$ & $\mathbf{0 , 0 0}$ & $\mathbf{0 , 0 0}$ \\
\hline Custo variável $(A+B+C=D)$ & $\mathbf{0 , 0 0}$ & $\mathbf{0 , 0 0}$ & $\mathbf{0 , 0 0}$ \\
\hline \multicolumn{4}{|l|}{ IV - Depreciações } \\
\hline 1 - Depreciação de benfeitorias/instalações & 0,00 & 0,00 & 0,00 \\
\hline 2 - Depreciação de implementos & 0,00 & 0,00 & 0,00 \\
\hline 3 - Depreciação de máquinas & 0,00 & 0,00 & 0,00 \\
\hline Total de depreciações (E) & $\mathbf{0 , 0 0}$ & $\mathbf{0 , 0 0}$ & $\mathbf{0 , 0 0}$ \\
\hline \multicolumn{4}{|l|}{ V - Outros custos fixos } \\
\hline 1 - Manutenção periódica de máquinas/implementos & 0,00 & 0,00 & 0,00 \\
\hline 2 - Encargos sociais & 0,00 & 0,00 & 0,00 \\
\hline 3 - Seguro do capital fixo & 0,00 & 0,00 & 0,00 \\
\hline Total de outros custos fixos (F) & $\mathbf{0 , 0 0}$ & $\mathbf{0 , 0 0}$ & $\mathbf{0 , 0 0}$ \\
\hline Custo fixo $(E+F=G)$ & $\mathbf{0 , 0 0}$ & $\mathbf{0 , 0 0}$ & $\mathbf{0 , 0 0}$ \\
\hline Custo operacional $(D+G=\mathbf{H})$ & $\mathbf{0 , 0 0}$ & $\mathbf{0 , 0 0}$ & $\mathbf{0 , 0 0}$ \\
\hline \multicolumn{4}{|l|}{ VI - Renda de fatores } \\
\hline 1 - Remuneração esperada sobre capital fixo & 0,00 & 0,00 & 0,00 \\
\hline $2-$ Terra & 0,00 & 0,00 & 0,00 \\
\hline Total de renda de fatores (I) & $\mathbf{0 , 0 0}$ & $\mathbf{0 , 0 0}$ & $\mathbf{0 , 0 0}$ \\
\hline Custo total $(\mathbf{H}+\mathbf{I}=\mathbf{J})$ & $\mathbf{0 , 0 0}$ & $\mathbf{0 , 0 0}$ & $\mathbf{0 , 0 0}$ \\
\hline
\end{tabular}

Fonte: Conab (2014). 
Os custos fixos são diferenciados em depreciação do capital fixo e demais custos fixos envolvidos na produção e remuneração dos fatores terra e capital fixo (tabela 2). Em termos econômicos, os componentes do custo são agrupados de acordo com sua função no processo produtivo dentro das categorias de custos variáveis: custos fixos, custo operacional e custo total. Nos custos variáveis, são agrupados todos os componentes que participam do processo ao longo do desenvolvimento da atividade, ou seja, aqueles que somente ocorrem ou incidem se houver produção. Enquadram-se aqui os itens de custeio, as despesas de pós-colheita e as despesas financeiras, constituindo-se, em curto prazo, em uma condição necessária para que o produtor continue na atividade (Conab, 2010b).

Nos custos fixos, enquadram-se os elementos de despesas que são suportados pelo produtor, independentemente do volume de produção, tais como depreciação e seguros. O custo operacional é composto de todos os itens de custos variáveis (despesas diretas), somado à parcela dos custos fixos diretamente associados à implementação da lavoura. Este último difere do custo total por não contemplar a renda dos fatores fixos, consideradas como remuneração esperada sobre o capital fixo e sobre a terra.

Em se tratando do custo total de produção, compreendese o somatório do custo operacional mais a remuneração atribuída aos fatores de produção. Numa perspectiva de longo prazo, todos esses itens devem ser considerados na formulação de políticas para o setor (Conab, 2010a).

$\mathrm{Na}$ formulação do método de cálculo dos custos de produção, o objetivo é a determinação do custo médio por unidade de comercialização das principais culturas constantes da pauta da PGPM, inclusive para os produtos não madeireiros assistidos pela política. Dessa maneira se quantifica o valor da subvenção que deverá ser paga ao produtor.

De acordo com a Lei ${ }^{\circ} 11.775$, de 17 de setembro de 2008 (Brasil, 2008), em seus artigos 48 e 54, autorizase a modalidade de subvenção direta, que prevê ao extrativista, enquadrado nos termos do art. $3^{\circ}$, da Lei $\mathrm{n}^{\circ}$ 11.326, de 24 de julho de 2006 (Brasil, 2006), o recebimento de subvenção, ao comprovar que efetuou a venda de seu produto por preço inferior ao preço mínimo fixado pelo Governo Federal (Instituto Brasileiro de Administração Municipal, 2013).

O cálculo do valor da subvenção é obtido pela seguinte fórmula, indicado por (Conab, 2010a):

$$
\mathrm{Vsu}=\mathrm{QLi} .(\mathrm{PMi}-\mathrm{Pme})
$$

Onde: $\mathrm{Vsu}=$ Valor da subvenção a ser paga em $\mathrm{R} \$$;

QLi = Quantidade líquida do produto objeto da subvenção em kg;

PMi $=$ Preço mínimo fixado pelo Governo Federal em $\mathrm{R} \$ \mathrm{~kg}^{-1}$;

Pme $=$ Preço constante na nota fiscal de venda ou de compra, em $\mathrm{R} \$ \mathrm{~kg}^{-1}$.

A partir dos conceitos e com base nas leis vigentes e padrões exigidos descritos, o cálculo dos custos de produção do pinhão deve ser realizado. Por conseguinte, aplicou-se a fórmula para obtenção do valor que deveria se constituir na subvenção, caso fosse positiva a inclusão do pinhão na PGPM.

\section{Resultados e discussão}

Para mensuração dos custos de produção do pinhão, a Conab (2010a) utiliza o critério de determinação dos custos explícitos, ou seja, aqueles diretamente desembolsados pelo produtor durante o processo (insumos, mão de obra temporária, entre outros). Os custos implícitos são aqueles não diretamente desembolsados, como depreciação de benfeitorias, máquinas, remuneração da terra e outros. Para efeito do produto "in natura", o custo de produção referese às despesas de coleta (catação e derrubada de pinhas, ensaque dos pinhões e transporte floresta/ casa), ou seja, basicamente mão-de-obra. Acrescentase à formação do custo, despesas com aquisição de material/equipamentos para a extração, transporte, armazenamento e acondicionamento, depreciação de equipamentos, remuneração esperada sobre o capital fixo e o custo da terra. Na tabela 3 são apresentados os cálculos do custo de produção de pinhão levantados em campo, de acordo com a estrutura utilizada pela Conab (2010a). 
Tabela 3. Custo de extração do pinhão, na região Sudeste e parte da região Centro-Sul do Paraná, baseado na metodologia adotada pela companhia nacional de abastecimento.

\begin{tabular}{|c|c|c|c|}
\hline Discriminação & Valor (R\$) & $\begin{array}{c}\text { Valor } \\
\left(\mathrm{R} \$ \mathrm{~kg}^{-1}\right)\end{array}$ & $\begin{array}{l}\text { Part. } \\
\text { (\%) }\end{array}$ \\
\hline \multicolumn{4}{|l|}{ I - Despesas de custeio da atividade extrativista } \\
\hline 1 - Operação com avião & 0,00 & 0,00 & 0,00 \\
\hline 2 - Operação com máquinas próprias & 0,00 & 0,00 & 0,00 \\
\hline 3 - Aluguel de máquinas/serviços & 0,00 & 0,00 & 0,00 \\
\hline 4 - Operação com animais próprios & 0,00 & 0,00 & 0,00 \\
\hline 5 - Operação com animais alugados & 0,00 & 0,00 & 0,00 \\
\hline 6 - Mão-de-obra & 35,00 & 0,84 & 71,69 \\
\hline 7 - Mão-de-obra fixa & 0,00 & 0,00 & 0,00 \\
\hline 8 - Sementes & 0,00 & 0,00 & 0,00 \\
\hline 9 - Fertilizantes & 0,00 & 0,00 & 0,00 \\
\hline 10- Agrotóxicos & 0,00 & 0,00 & 0,00 \\
\hline 11 - Outras despesas (luvas, capacete, bota) & 2,00 & 0,04 & 4,10 \\
\hline 12 - Outros itens & 0,00 & 0,00 & 0,00 \\
\hline Total das despesas de custeio (A) & 37,00 & $\mathbf{0 , 8 8}$ & 75,79 \\
\hline \multicolumn{4}{|l|}{ II - Despesas pós-coleta } \\
\hline 1 - Seguro agrícola & 0,00 & 0,00 & 0,00 \\
\hline 2 - Assistência técnica & 0,00 & 0,00 & 0,00 \\
\hline 3 - Transporte externo & 4,78 & 0,10 & 9,79 \\
\hline 4 - Armazenagem & 0,35 & 0,01 & 0,72 \\
\hline 5 - CESSR & 0,00 & 0,00 & 0,00 \\
\hline 6 - Impostos & 0,00 & 0,00 & 0,00 \\
\hline $7-$ Taxas & 0,00 & 0,00 & 0,00 \\
\hline 8 - Outros & 1,00 & 0,02 & 2,05 \\
\hline Total das despesas pós-coleta (B) & 6,13 & 0,12 & 12,56 \\
\hline \multicolumn{4}{|l|}{ III - Despesas financeiras } \\
\hline $1-$ Juros & 0,00 & 0,00 & 0,00 \\
\hline Total das despesas financeiras $(\mathrm{C})$ & $\mathbf{0 , 0 0}$ & $\mathbf{0 , 0 0}$ & $\mathbf{0 , 0 0}$ \\
\hline Custo variável $(A+B+C=D)$ & 43,13 & 1,00 & 88,34 \\
\hline \multicolumn{4}{|l|}{ IV - Depreciações } \\
\hline 1 - Depreciação de benfeitorias/instalações & 0,00 & 0,00 & 0,00 \\
\hline 2 - Depreciação de implementos & 0,00 & 0,00 & 0,00 \\
\hline 3 - Depreciação de máquinas & 1,66 & 0,03 & 3,40 \\
\hline Total de depreciações (E) & 1,66 & 0,03 & 3,40 \\
\hline \multicolumn{4}{|l|}{ V - Outros custos fixos } \\
\hline 1 - Manutenção periódica de máquinas/implementos & 0,00 & 0,00 & 0,00 \\
\hline 2 - Encargos sociais & 0,00 & 0,00 & 0,00 \\
\hline 3 - Seguro do capital fixo & 0,00 & 0,00 & 0,00 \\
\hline Total de outros custos fixos (F) & $\mathbf{0 , 0 0}$ & $\mathbf{0 , 0 0}$ & $\mathbf{0 , 0 0}$ \\
\hline Custo fixo $(E+F=G)$ & 1,66 & $\mathbf{0 , 0 3}$ & 3,40 \\
\hline CUSTO operacional $(D+G=\mathbf{H})$ & 44,79 & 1,04 & 91,74 \\
\hline \multicolumn{4}{|l|}{ VI - Renda de fatores } \\
\hline 1 - Remuneração esperada sobre capital fixo & 2,69 & 0,00 & 0,00 \\
\hline $2-$ Terra & 1,34 & 0,03 & 2,75 \\
\hline Total de renda de fatores (I) & 4,03 & $\mathbf{0 , 0 8}$ & 8,26 \\
\hline Custo total $(H+I=J)$ & 48,82 & 1,12 & 100,00 \\
\hline
\end{tabular}

Fonte: Conab (2010a).

O principal item no custo da atividade extrativa é a mão-de-obra, com uma participação de $71,69 \%$ do custo total de extração. Sendo assim, pode-se dizer que o produtor/coletor está sendo remunerado com base no custo da mão de obra, visto que o mesmo no ano de
2011 para a região de estudo foi em média $\mathrm{R} \$ 35,00$ referentes a diária de trabalho em campo.

De acordo com Silva et al. (2013), em estudo sobre o potencial de extrativismo da castanha-do-pará, as atividades realizadas no interior da floresta são as que 
mais resultam em despesas, alcançando até $85,64 \%$ do custo total. Os autores ainda apontam que a principal despesa é a mão de obra para a coleta, que pode atingir até $68,13 \%$, ficando em segundo lugar as despesas com transporte e comercialização, representando até 12,86\% das despesas totais. Observa-se uma grande semelhança entre os resultados encontrados em relação ao estudo apresentado (diferença de $2 \%$ na mão de obra e de $0,30 \%$ nas despesas de transporte e comercialização), abrindo importantes precedentes à relevância desses fatores. Importante adicionar ainda que, segundo Conab (2013), a produção de castanha-do-brasil (70\%), uauá $(63,14 \%)$ e baru $(56,59)$ detém igualmente elevada representação do custo de mão de obra. De maneira objetiva, a mão de obra é um importante insumo na produção PFNM, sendo assim fator determinante no custo total de produção.

A participação da coleta do pinhão na composição da renda da propriedade é, em média, $3,24 \%$ da renda bruta anual. Assim, fica claro que na composição da renda dos entrevistados, essa atividade não é representativa, ao contrário do apontado por Guerra et al. (2002), quando afirmaram que o pinhão é importante fonte de renda para pequenos produtores. Um possível fator motivador é o baixo preço pago ao produtor rural, ao contrário do valor pago em 2001/2002, quando se constituía em praticamente o dobro do valor recebido por $\mathrm{kg}$ de pinhão do que durante a pesquisa atual. Mesmo com preços baixos, os produtores comercializavam o pinhão principal junto ao mercado atacadista, que pagava em média $\mathrm{R} \$ 0,97$ por $\mathrm{kg}$ do pinhão colhido em suas propriedades. A participação do pinhão na composição da renda bruta anual variou de 0,41 a $17,95 \%$, mas em média não ultrapassou o valor de $75 \%$ do salário mínimo do IBGE de R\$622,00 em 2010.

De acordo com os entrevistados, não compensaria transportar a semente para venda em centros urbanos e por esta razão a comercialização é realizada diretamente com os atacadistas. Os mesmos afirmam que em se tratando de uma fonte de renda perdida, se não explorada, acaba sendo realizada como é possível.

A atividade política, por meio da PGPM poderia beneficiar os produtores, que ao invés de uma exploração de pouco rendimento, poderiam ter remuneração justa. Segundo Costa et al. (2013), a PGPM para a cera de carnaúba beneficia produtores individuais, cooperativas e associações formais nos estados do Piauí, Ceará e Rio Grande do Norte. Considerando as mudanças ocorridas desde 2009 dos custos de produção e criação da política de garantia de preços mínimos da Sociobiodiversidade (PGPM-Bio), os preços mínimos aumentaram substancialmente, aproximando-se mais dos preços de mercado. A subvenção direta ao extrativista foi muito importante para a melhora do processo.

Com base nos dados de custos apresentados na Tabela 3, o custo de produção do pinhão é de $\mathrm{R} \$ 1,12 \mathrm{~kg}^{-1}$, superior à média de preços $(\mathrm{R} \$ 0,97)$ fornecida pelos produtores e coletores durante a coleta de dados em campo.

Em um primeiro momento, este tipo de trabalho por parte dos envolvidos não é caracterizado de grande atratividade econômica. Isso se deve ao fato da remuneração obtida ser pouco satisfatória, de maneira que os produtores e coletores não estariam sendo remunerados a contento. Entretanto, isso pode estar relacionado à tradição familiar, bem como à falta de interesse em outras atividades econômicas. Em estudo da Conab (2014) é evidenciado que o fator da mão-deobra familiar está presente em quase $100 \%$ dos casos da produção de não madeireiros, podendo alterar os custos de produção pelo custo de mão-de-obra não ser incluído diretamente na soma de forma linear.

Desse modo, verificou-se que o preço do pinhão nas áreas visitadas está abaixo do custo de produção médio calculado, conforme a metodologia utilizada por Conab (2010a) para o cálculo dos custos de produção para produtos extraídos da sociobiodiversidade.

Em se tratando do fluxo de aprovação de um produto, para que o mesmo passe a integrar a lista daqueles que são contemplados pela PGPM, tem-se o seguinte esquema:

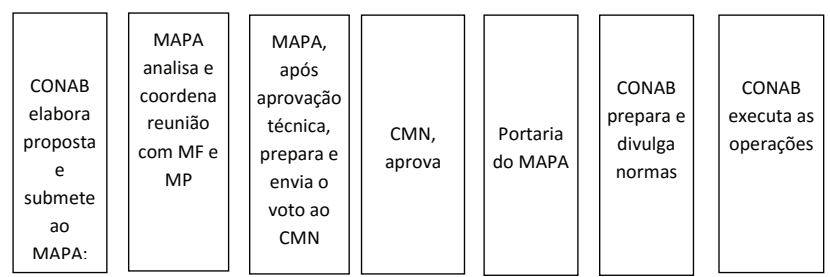

Figura 1. Fluxo para aprovação dos preços mínimos, adaptado de Tavares (2012).

O governo tem suas ações conhecidas como de intervenção governamental. Essas podem ter o intuito de formação de estoques (tabela 4), ou de operações de escoamento (subvenção) (tabela 5). No caso desse estudo, sendo a segunda parte a que mais interessa. 
Tabela 4. Ações governamentais para formação de estoques.

\begin{tabular}{|c|c|c|c|c|}
\hline Formação de estoque & O que é & Execução & Beneficiários & $\begin{array}{l}\text { Como manifestar } \\
\text { interesse em vender }\end{array}$ \\
\hline $\begin{array}{l}\text { Aquisição do governo } \\
\text { federal (AGF) }\end{array}$ & $\begin{array}{c}\text { Aquisição direta de } \\
\text { produtos da pauta da } \\
\text { PGPM }\end{array}$ & $\begin{array}{l}\text { Operada quando o preço } \\
\text { de mercado estiver } \\
\text { inferior ao mínimo } \\
\text { fixado, mediante } \\
\text { alocação de recursos } \\
\text { pelo Tesouro Nacional }\end{array}$ & $\begin{array}{l}\text { Produto rural, produtor } \\
\text { da Agricultura Familiar } \\
\text { e/ou suas cooperativas }\end{array}$ & $\begin{array}{l}\text { Informar por telefone } \\
\text { diretamente ou por } \\
\text { associação }\end{array}$ \\
\hline $\begin{array}{c}\text { Contrato público de } \\
\text { opção de venda (COV) }\end{array}$ & $\begin{array}{l}\text { Seguro de preço para } \\
\text { data futura, dá o direito } \\
\text { mas não a obrigação de } \\
\text { vender ao Governo }\end{array}$ & $\begin{array}{l}\text { Se a expectativa de } \\
\text { preços futuros for } \\
\text { menor que o Preço de } \\
\text { Exercício }\end{array}$ & $\begin{array}{l}\text { Produtor rural e/ou suas } \\
\text { cooperativas que serão } \\
\text { os titulares dos contratos }\end{array}$ & $\begin{array}{l}\text { Indicar um corretor e } \\
\text { credenciar-se junto à } \\
\text { bolsa }\end{array}$ \\
\hline
\end{tabular}

Fonte: Bacha \& Cadarelli (2008)

Tabela 5. Ações governamentais para operações de escoamento.

\begin{tabular}{|c|c|c|c|c|}
\hline $\begin{array}{c}\text { Operações de } \\
\text { escoamento }\end{array}$ & O que é & Lançamento & Beneficiários & Como participar \\
\hline $\begin{array}{l}\text { Prêmio de escoamento } \\
\text { da produção (PEP) }\end{array}$ & $\begin{array}{l}\text { Subvenção econômica } \\
\text { para escoamento de } \\
\text { produto do local de } \\
\text { produção para o de } \\
\text { consumo }\end{array}$ & $\begin{array}{l}\text { Quando o preço de } \\
\text { mercado estiver abaixo } \\
\text { do mínimo }\end{array}$ & $\begin{array}{c}\text { Os segmentos definidos } \\
\text { no aviso }\end{array}$ & $\begin{array}{c}\text { Ter um corretor } \\
\text { nomeado, ser cadastrado } \\
\text { na bolsa, estar regular } \\
\text { no SICAF, SIRCOI e } \\
\text { CADIN e ter fornecedor } \\
\text { do produto }\end{array}$ \\
\hline $\begin{array}{l}\text { Prêmio Equalizador } \\
\text { Pago ao Produtor } \\
\text { (PEPRO) }\end{array}$ & $\begin{array}{l}\text { Subvenção econômica } \\
\text { para escoamento de } \\
\text { produto do local de } \\
\text { produção para o de } \\
\text { consumo }\end{array}$ & $\begin{array}{l}\text { Quando o preço de } \\
\text { mercado } \\
\text { estiver abaixo do } \\
\text { mínimo }\end{array}$ & $\begin{array}{c}\text { Produtor rural e/ou sua } \\
\text { cooperativa }\end{array}$ & $\begin{array}{c}\text { Ter um corretor } \\
\text { nomeado, ser cadastrado } \\
\text { na bolsa, estar regular } \\
\text { no SICAF, SIRCOI e } \\
\text { CADIN e ter fornecedor } \\
\text { do produto }\end{array}$ \\
\hline
\end{tabular}

SICAF - Sistema de Cadastramento Unificado de Fornecedores; SIRCOI - Sistema de Registro e Controle de Inadimplentes; CADIN - Cadastro de Inadimplentes. Fonte: Bacha \& Cadarelli (2008).

Finalmente, tomando-se por base que o preço mínimo hipotético representasse exatamente o custo de produção calculado ( $\mathrm{R} \$ 1,12 \mathrm{~kg}^{-1}$ ) nesse trabalho, naquele momento haveria a necessidade da subvenção do governo para o pagamento da diferença de $\mathrm{R} \$ 0,13 \mathrm{~kg}^{-1}$ ao produtor e ao coletor que vendesse sua produção ao varejo (preço médio de $\mathrm{R} \$ 0,99 \mathrm{~kg}^{-1}$ ) e $\mathrm{R} \$ 0,18 \mathrm{~kg}^{-1}$ ao produtor/coletor que vendesse a produção ao atacadista (preço médio de $\mathrm{R} \$ 0,94 \mathrm{~kg}^{-1}$ ). Sendo assim, toda a comercialização, seja disponibilizada por produtores ou coletores, estaria sujeita à complementação da PGPM. Em uma análise histórica da evolução dos preços do pinhão (Figura 2), podemos inferir a influência desse fator na elaboração de planos de apoio.

Analisando-se o preço que vem decrescendo nos últimos anos, poder-se-ia assumir que dificilmente a realidade encontrada agora seria diferente daquela observada em 2010. Em relatório produzido por Conab (2014), pode-se encontrar o custo atual de produção do pinhão, que atinge valor médio de $\mathrm{R} \$ 2,26 \mathrm{~kg}^{-1}$. Porém, encontram-se ainda casos onde o preço mínimo estabelecido pelo estudo da Conab não é pago ao produtor, como em Guarapuava onde o valor pago ao produtor não ultrapassa $\mathrm{R} \$ 1,50 \mathrm{~kg}^{-1}$. 


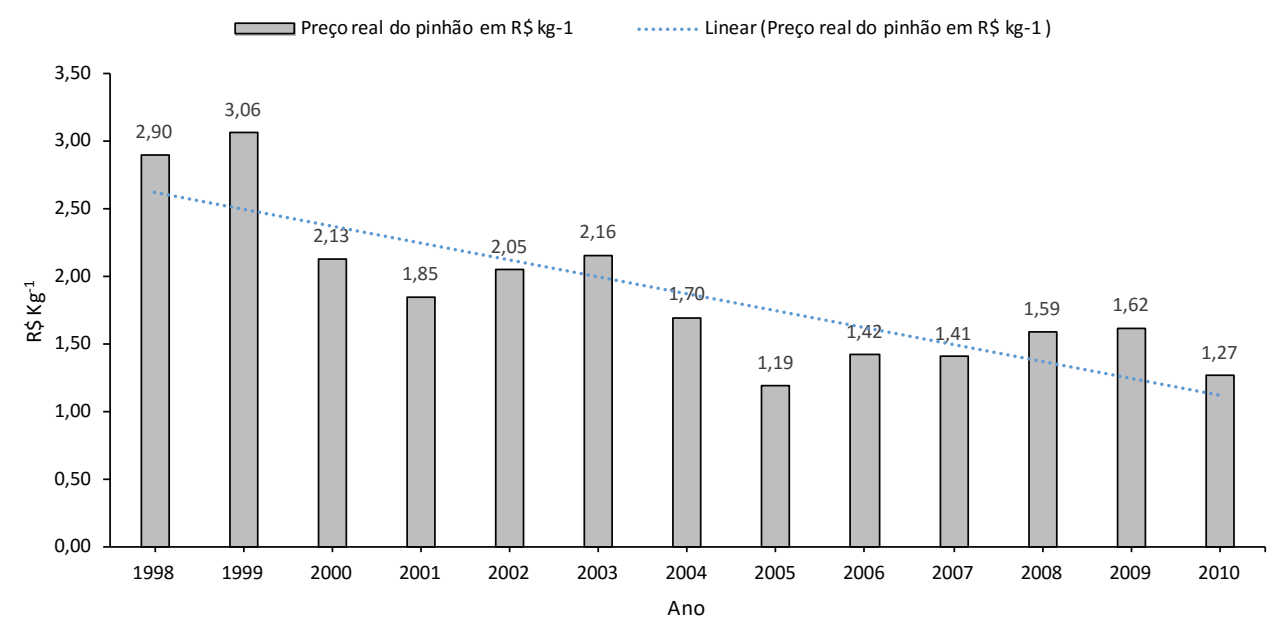

Figura 2. Evolução do preço do pinhão no Estado do Paraná, no período de 1998 a 2010. Fonte: Paraná (2012). Preços corrigidos com base no Índice Geral de Preços do Mercado (IGP-M).

Mesmo passados quase quatro anos da pesquisa, sem uma política de incentivo e organização da produção/ extração dificilmente os extratores conseguirão espaço no mercado, eliminando intermediários e alcançando melhores preços pelo produto. Aplicando-se o valor do preço mínimo hipotético ora calculado para o pinhão e novamente tomando, por exemplo, que este seria o preço mínimo fixado pelo Governo Federal para a Safra 2010/2011 para pagamento por kg de pinhão aos coletores/produtores das Mesorregiões Sudeste e Centro Sul do Paraná, verifica-se que a renda bruta mensal obtida pela maioria das famílias tanto do tipo coletor/extrativista como do tipo produtor/extrativista ultrapassaria o salário mínimo nacional e estadual, supondo que um coletor coletasse em média $50 \mathrm{~kg} \mathrm{dia}^{-1}$ em 20 dias mês ${ }^{-1}$. Essa renda pode ser ainda maior, uma vez que normalmente o trabalho é realizado pela família e o volume coletado supera aquele montante. Ressalta-se que o custo calculado é apenas uma base de comparação para o estabelecimento do preço mínimo pelas autoridades competentes.

Face ao exposto, é premente que os órgãos responsáveis pela PGMP-bio envidem esforços para a inclusão do pinhão nesta política, pois produtores estão desestimulados a explorá-lo e coletores já recebem menos do que o custo de produção do pinhão. $\mathrm{O}$ Governo pode contribuir com a efetivação da inclusão do pinhão na PGPMbio e a sociedade civil atuando com respeito e incentivando o consumo do pinhão apenas após o início previsto em lei para a extração e comercialização deste produto. A institucionalização do uso do pinhão na merenda escolar estadual, tal qual ocorre no estado do Acre com a aquisição do açaí pelo governo do estado, pode ser uma alternativa.

Caso o pinhão seja efetivamente incluído entre os produtos amparados pela PGPM-Bio, uma vez que estudos sobre os custos de produção do pinhão já estão sendo realizados pela Conab, espera-se manter o estímulo à exploração deste importante PFNM, auxiliando no desenvolvimento econômico e social sustentado das comunidades extrativistas, através da geração de renda, da melhoria da qualidade de vida das comunidades, da fixação dos envolvidos no meio rural, ao mesmo tempo em que ajuda a promover a exploração sustentável e a valorização das áreas florestais, conservando os poucos remanescentes de Floresta Ombrófila Mista do estado do Paraná.

\section{Conclusões}

A subvenção da produção do pinhão incluindo o mesmo na PGPM, apresenta-se como uma ferramenta importante, uma vez que os preços médios pagos aos produtores e extratores se mostraram abaixo do custo de produção.

Sendo o pinhão incluído na PGPM, haverá a melhora no bem-estar econômico e social dos envolvidos na extração e comercialização. Outro fator benéfico é a conservação dos remanescentes florestais de Floresta Ombrófila Mista (FOM) do estado, uma vez que a floresta passará a ser mais valorizada por seus PFNM`s. 
Sugere-se estimular a organização dos produtores/ coletores em associações ou cooperativas a fim de aumentar o poder de negociação de preços do pinhão junto aos compradores, aumentar a escala de produção, auxiliar a difusão de informações, facilitar o acesso ao crédito, assistência técnica e à política de preços mínimos; aspectos essenciais ao bom desempenho da cadeia produtiva.

\section{Referências}

ASSOCIAÇÃO DE PRESERVAÇÃO DO MEIO AMBIENTE E DA VIDA. Planejando propriedades e paisagens. Rio do Sul, 2005.

BACHA, C. J. C.; CALDARELLI, C. E. Avaliação do desempenho dos novos instrumentos de política de garantia de preços agrícolas de 2004 a 2007. In: CONGRESSO DA SOCIEDADE BRASILEIRA DE ECONOMIA, ADMINISTRAÇÃO E SOCIOLOGIA RURAL, 46., 2008, Rio Branco, AC. Amazônia, mudanças globais e agronegócios: o desenvolvimento em questão. Rio Branco, AC: SOBER, 2008. 1. Disponível em: <http://www.sober.org.br/ palestra/9/409.pdf>. Acesso em: 15 dez. 2015.

BRASIL. Lei $n^{\circ} 8.629$, de 25 de fevereiro de 1993. Dispõe sobre a regulamentação dos dispositivos constitucionais relativos à reforma agrária, previstos no Capítulo III, Título VII, da Constituição Federal. Diário Oficial [da] República Federativa do Brasil, Brasília, DF, n. 38, 26 fev. 1993.

BRASIL. Lei $\mathrm{n}^{\mathrm{o}} 11.775$, de 17 de setembro de 2008. Institui medidas de estímulo à liquidação ou regularização de dívidas originárias de operações de crédito rural e de crédito fundiário [...] e dá outras providências. Diário Oficial [da] República Federativa do Brasil, Brasília, DF, n. 181, 18 set. 2008.

BRASIL. Lei $n^{\circ} 11.326$, de 24 de julho de 2006. Estabelece as diretrizes para a formulação da Política Nacional da Agricultura Familiar e Empreendimentos Familiares Rurais. Diário Oficial [da] República Federativa do Brasil, Brasília, DF, n. 141, 25 jul. 2006.

CONAB (Brasil). Custos de produção agrícola: a metodologia da Conab. Brasília, DF, 2010a. 60 p. Disponível em: $<$ http://www.conab. gov.br/OlalaCMS/uploads/arquivos/0086a569bafb14cebf87bd1119 36e115..pdf.> Acesso em 15 dez. 2015.

CONAB (Brasil). Pinhão (semente). Conjuntura Especial, set. 2014. Brasília, DF, 2014. Disponível em: <http://www.conab. gov.br/OlalaCMS/uploads/arquivos/14_09_09_12_36_06_ pinhaosementesetembro_2014.pdf.> Acesso em: 15 dez. 2015.

CONAB. (Brasil). Proposta de preços mínimos: safra 2013/2014 (produtos da sociobiodiversidade). Brasília, DF, 2013. v. 2. Disponível em: <http://www.conab.gov.br/OlalaCMS/uploads/ arquivos/13_11_22_15_25_35_pm_sociobio_13_14.pdf $>$. Acesso em: $15 \mathrm{dez}$

CONAB (Brasil). Título 35: subvenção direta ao produtor extrativista (SDPE). Comunicado CONAB/MOC N. ${ }^{\circ}$ 021, de 16/08/2010. Brasília, DF, 2010b. Disponível em: <http://www.conab.gov.br/ OlalaCMS/uploads/arquivos/11_07_18_08_43_06_titulo_35..pdf $>$. Acesso em 15 dez. 2015.

Pesq. flor. bras., Colombo, v. 35, n. 84, p. 459-468, out./dez. 2015
COSTA, S. L. V.; SOARES, O. F. T.; GOMES, A. M. J. Política de garantia de preços mínimos para cera de carnaúba: comparação entre preços mínimos e preços de mercado das safras de 2003/2004 2011/2012. Revista Eletrônica Informe Econômico, v. 1, n. 1, ago. 2013. Disponível em: <www.ojs.ufpi.br/index.php/economiaufpi/ article/download/1285/1009>. Acesso em: 20 dez. 2015.

GIL, A. C. Métodos e técnicas de pesquisa social. 6. ed. São Paulo: Atlas, 2009.

GUERRA, M. P.; SILVEIRA, V.; REIS, M. S.; SCHNEIDER, L. Exploração, manejo e conservação da araucária (Araucaria angustifolia). In: SIMÕES, L. L.; LINO, C. F. (Org.). Sustentável Mata Atlântica: a exploração de seus recursos florestais. São Paulo: SENAC São Paulo, 2002. p. 85-101.

IBGE. Contas regionais do Brasil: 2010. Rio de Janeiro, 2010a. Disponível em: $<$ http://www.ibge.gov.br/home/estatistica/economia/ pevs/2010/default_zip_meso.shtm>. Acesso em: 15 dez. 2010.

IBGE. Estimativa das populações residentes em 2009 segundo os municípios. Rio de Janeiro, 2009. Disponível em: $<$ http://www.ibge. gov.br/home/estatistica/populacao/estimativa2009/POP2009_DOU. pdf>. Acesso em: 15 dez. 2010.

IBGE. Produção da extração vegetal e da silvicultura 2010. Rio de Janeiro, 2010b. Disponível em: <http://www.ibge.gov.br/home/ estatistica/economia/pevs/2010/default_zip_meso.shtm>. Acesso em: 15 dez. 2010.

INCRA. Instrução especial $\mathbf{n}^{\circ} \mathbf{2 0}$ de $\mathbf{2 8}$ de maio de 1980. Estabelece o Módulo Fiscal de cada Município, previsto no Decreto nº 84.685 de 06 de maio de 1980. Disponível em: <http:/www.incra.gov.br/media/ institucional/legislacao/atos_internos/instrucoes/instrucao_especial/ IE20_280580.pdf $>$. Acesso em: 15. fev. 2010.

INSTITUTO BRASILEIRO DE ADMINISTRAÇÃO MUNICIPAL. Mapeamento de oportunidades para gestão ambiental adequada na Amazônia Legal. (Papers de referência, 1). Disponível em: $<$ http://www.amazonia-ibam.org.br/images/pqga/arquivos/ mapeamento_volume_1_politicas_planos_programas_incentivos. pdf $>$. Acesso em: 15 dez. 2015.

LOPES, P. A. Probabilidades \& estatística. Rio de Janeiro: Reichman \& Affonso, 1999

PARANÁ. Secretaria de Estado da Agricultura e Abastecimento. Departamento de Economia Rural. Boletim do pinhão, 2012. Disponível em: <http://www.agricultura.pr.gov.br/arquivos/File/ deral/pinhao.pdf>. Acesso em: 15 dez. 2015

PÉLLICO NETO, S.; BRENA, D. A. Inventário florestal. Curitiba, 1997. 316 p.

SESC (Paraná). Inventário cultural. Disponível em: $<$ http://www. sescpr.com.br/inventario/regioes.php? $\operatorname{cod}=9>$. Acesso em: 30 set. 2010.

SILVA, A. A.; SANTOS, M. K. V.; GAMA, J. R. V.; NOCE, R.; LEÃO, S. Potencial do extrativismo da castanha-do-pará na geração de renda em comunidades da mesorregião baixo Amazonas, Pará. Floresta e Ambiente, Seropédica, v. 20, n. 4, p. 500-509, Dec. 2013. DOI: 10.4322/floram.2013.046.

TAVARES, C. E. Política de garantia de preços mínimos para produtos da sociobiodiversidade - PGPM. Brasília, DF: CONAB, 2012. Disponível em: < http://www.agricultura.gov.br/ arq_editor/file/camaras_setoriais/Cacau/23RO/App_Filosofia $\% 20$ C\%C3\%A2mara\%20Cacau.pdf > . Acesso em: 02 Jun. 2015. 